\title{
IMPLEMENTASI PEMBELAJARAN PKBM BERBASIS BUDAYA GUNA MENDUKUNG PELESTARIAN BUDAYA DI PKBM WIRATAMA YOGYAKARTA
}

\section{CLC BASED LEARNING IMPLEMENTATION SUPPORT FOR CULTURAL PRESERVATION OF CULTURE IN YOGYAKARTA PKBM WIRATAMA}

Oleh: Noni Feliani, Pendidikan Luar Sekolah, Universitas Negeri Yogyakarta, nonifelianis@gmail.com

\begin{abstract}
Abstrak
Penelitian ini bertujuan untuk mendeskripsikan Implementasi pembelajaran PKBM berbasis budaya dengan cara mendeskripsikan proses pelaksanaan kegiatan, faktor pendukung dan faktor penghambat PKBM berbasis budaya guna mendukung pelestarian budaya di PKBM Wiratama Yogyakarta. Penelitian ini menggunakan metode kualitatif. Pengumpulan data dilakukan dengan teknik pengamatan atau observasi, wawancara, dan dokumentasi dengan subyek ketua PKBM, pengelola, tutor dan warga belajar. Pembuktian keabsahan data menggunakan teknik trianggulasi. Analisis data yang digunakan adalah analisis kualitatif dengan langkah pengumpulan data, reduksi data, display data, dan penarikan kesimpulan. Hasil penelitian yang diperoleh dalam penelitian ini adalah: (1) Implementasi pembelajaran pendidikan berbasis budaya di PKBM Wirtama yang terdiri dari; (a) Persiapan dalam pembelajaran pendidikan berbasis budaya, merencanakan proses pelaksanaan pembelajaran membatik (b) Pelaksanaan pendidikan berbasis budaya dalam hal ini adalah membatik dimulai dengan cara tutor menyampaikan materi tentang membatik baik secara materi maupun praktik. Tutor menjelaskan tentang materi dan media yang digunakan dalam pembelajaran, serta mendampingi warga belajar dalam proses pembelajaran yang sedang berlangsung. (c) Evaluasi dilaksanakan diakhir pembelajaran pendidikan berbasis budaya dilakukan dengan cara berdiskusi mengenai permasalahan yang sedang dihadapi serta mencari solusi permasalahan. (2) faktor pendukung pelaksanaan pendidikan berbasis budaya di PKBM Wiratama adalah sebagai berikut: kompetensi tutor yang memadai dalam melaksanakan pembelajaran membatik, strategi pelaksanaan pembelajaran yang sesuai dengan situasi dan kondisi warga belajar, sarana dan prasana pembelajaran yang sudah tersedia. Faktor penghambat pelaksanaan pendidikan berbasis budaya di PKBM Wiratama adalah kurangnya dana untuk membeli alat dan bahan keperluan untuk pembelajaran dan cuaca buruk atau hujan.
\end{abstract}

Kata kunci: Membatik, Pendidikan Berbasis budaya, Penelitian, PKBM

\begin{abstract}
This study aims to describe CLC-based learning implementation culture by describing the process of implementation, supporting factors and factors inhibiting CLC-based culture to support cultural preservation in PKBM wiratama Yogyakarta.This study uses a qualitative method. The data collection was done by using observation or observation, interviews, and documentation with the subject head of the CLC, managers, tutors and learners. Proof of the validity of the data using triangulation techniques. Analysis of the data used is qualitative analysis to measure data collection, data reduction, data display, and conclusion. The results obtained in this study are: (1) The management of culture-based education in PKBM Wirtama comprising; (A) Preparation of the learning culture based education plan implementation process of learning batik (b) The implementation of culturebased education in this regard is batik starting with how the tutor explained about batik both materially and practices. Tutor describes the materials and media used in learning, and assisting learners in the learning process is ongoing. (C) The evaluation was conducted at the end of culture-based education learning is done by discussing the problems being faced and to find solutions to problems. (2) factors supporting the implementation of culturebased education in PKBM wiratama are as follows: tutor adequate competence in implementing the learning batik, implementation of learning strategies appropriate to the situation and condition of learners, learning facilities and infrastructures that are already available. Factors inhibiting the implementation of culture-based education in wiratama CLC is the lack of funds to buy tools and materials for learning purposes and bad weather or rain.
\end{abstract}


Diklus: Jurnal Pendidikan Luar Sekolah, 1(1), Maret 2017 - 53

Noni Felani 



\section{Diklus: Jurnal Pendidikan Luar Sekolah, 1(1), Maret 2017 - 53 \\ Noni Felani}

\section{PENDAHULUAN}

Konsep pendidikan berbasis budaya adalah pendidikan yang diselenggarakan untuk memenuhi standar nasional pendidikan yang diperkaya dengan keunggulan komparatif dan kompetitif berdasar nilai-nilai luhur budaya agar peserta didik secara aktif dapat mengembangkan potensi diri sehingga menjadi manusia yang unggul, cerdas, visioner, peka terhadap lingkungan dan keberagaman budaya, serta tanggap terhadap lingkungan dan keberagaman budaya, serta tanggap terhadap perkembangan dunia. Program program kegiatan yang disusun oleh PKBM sebaiknya diarahkan pada pembudayaan masyarakat. Pembudayaan untuk belajar, pembudayaan untuk mandiri, dan pembudayaan terhadap nilai nilai budaya luhur yang ada di Daerah Istimewa Yogyakarta.

Pemerintah Daerah Istimewa Yogyakarta berusaha untuk mewujudkan masyarakat yang berpendidikan dan berkarakter sebagai konsekuensi dari perkembangan dewasa ini yang menuntut adanya Sumber Daya Manusia yang berkualitas agar mampu berinteraksi dan bersaing secara mantap dalam percaturan kehidupan global yang tiada lagi batas batas dinding kewilayahan. Kebudayaan dunia/global masuk ke Yogyakarta melalui berbagai cara, dan paling utama adalah melalui media massa dan teknologi infomasi. Arus kebudayaan yang tak terbendung ini berhadapan dengan nilai-nilai luhur budaya yang ada akan mengalami penyesuaianpenyesuaian melalui asosiasi, asimilasi maupun akulturasi.

Dalam kurun waktu berikutnya, sejalan dengan perubahan yang dialami Indonesia dan dunia internasional, banyak faktor lain yang mempengaruhi perkembangan Yogyakarta. Pemerintah daerah berusaha menjadikan Yogyakarta sebagai pusat pendidikan terkemuka tak hanya di Indonesia, tetapi juga di Asia Tenggara pada tahun 2025. Dengan demikian diharapkan akan terwujud masyarakat yang berkualitas sehingga dapat menjadi subjek pembangunan yang handal demi kelangsungan dan keberhasilan pembangunan di segala bidang.

Keinginan untuk melakukan penguatan dan pencerahan untuk kebaikan, kesejahteraan dan kebahagiaan ini diperkuat oleh adanya fenomena yang menunjukkan ketidakserasian perkembangan intelektualitas dengan perkembangan moral dan karakter, yang juga marak dan menggejala secara nasional. Untuk itu berkembang wacana untuk menjadikan Daerah Istimewa Yogyakarta sebagai pusat pendidikan berbasis budaya (lokal dan pluralistik yang ada dan tumbuh di Daerah Istimewa Yogyakarta) menjadi sangat kuat. Apabila keinginan ini terwujud, Daerah Istimewa Yogyakarta tidak saja menjadi tujuan wisata alam dan sejarah akan tetapi juga sebagai acuan orientasi pembangunan pendidikan dan sumber daya manusia yang 


\section{Diklus: Jurnal Pendidikan Luar Sekolah, 1(1), Maret 2017 - 54 \\ Noni Felani}

mendunia. Nilai nilai budaya diangkat dan digunakan secara tepat dan arif dalam mendasari dan melandasi pendidikan di Daerah Istimewa Yogyakarta.

Daerah Istimewa Yogyakarta (DIY) adalah provinsi yang mempunyai keistimewaan dalam penyelenggaraan urusan pemerintahan dalam kerangka Negara Kesatuan Republik Indonesia. Keistimewaan ini adalah keistimewaan kedudukan hukum yang dimiliki oleh DIY berdasarkan sejarah dan hak asal-usul menurut Undang-Undang Dasar Negara Republik Indonesia Tahun 1945 untuk mengatur dan mengurus kewenangan istimewa. Kewenangan istimewa ini merupakan wewenang tambahan tertentu yang dimiliki oleh DIY selain wewenang yang telah ditentukan dalam undang-undang tentang pemerintahan daerah ( http://yogyakarta.bpk.go.id : 2015)

Kewenangan DIY sebagai daerah otonom mencakup kewenangan dalam urusan Pemerintah Daerah DIY sebagaimana dimaksud dalam undang-undang tentang pemerintah daerah dan kewenangan urusan Keistimewaan yang telah ditetapkan dalam Undang-Undang Nomor 13 Tahun 2012.

Kewenangan dalam urusan Keistimewaan tersebut meliputi:

a. Tata cara pengisian jabatan, kedudukan, tugas, dan wewenang Gubernur dan Wakil Gubernur

b. Kelembagaan Pemerintah Daerah DIY

c. Kebudayaan

d. Pertanahan

e. Tata ruang

Pengaturan kewenangan dalam urusan Keistimewaan bertujuan untuk mewujudkan pemerintahan yang demokratis, mewujudkan kesejahteraan dan ketenteraman masyarakat, mewujudkan tata pemerintahan dan tatanan sosial yang menjamin ke-bhineka-tunggal-ikaan dalam kerangka Negara Kesatuan Republik Indonesia, menciptakan pemerintahan yang baik, dan melembagakan peran dan tanggung jawab Kasultanan dan Kadipaten dalam menjaga dan mengembangkan budaya Yogyakarta yang merupakan warisan budaya ( http://yogyakarta.bpk.go.id : 2015).

Peran pendidikan dalam mengenakan budaya lokal kepada masyarakat melalui lembaga PKBM menjadi hal perlu dilakukan dalam lembaga pendidikan. Salah satu upaya untuk menjaga kelestarian budaya lokal yaitu melalui pembelajaran berbasis budaya lokal. Kebudayaan daerah merupakan dasar perkembangan identitas suatu bangsa (Tilaar, 2002:5), sehingga perlu adanya pembinaan dan pengenalan budaya bangsa kepada generasi muda, dan masyarakat luas agar dapat melestarikan budaya bangsa ini.

Dalam sejarah dunia, bangsa besar yaitu bangsa yang menghargai kebudayaan sendiri, tidak meninggalkan budaya yang menjadi identitas bangsa. Bangsa Indonesia dulu dikenal sebagai bangsa yang ramah dan sopan oleh bangsa lain. Sikap saling menghormati, tepo seliro, gotong royong dan suka bermusyawarah kini semakin langka. Melihat kondisi bangsa Indonesia saat ini, kebudayaan yang dimiliki 


\section{Diklus: Jurnal Pendidikan Luar Sekolah, 1(1), Maret 2017 - 55}

Noni Felani

negeri ini telah ditinggalkan oleh masyarakat. Misal budaya yang mulai ditinggalkan yaitu tepo seliro, rasa saling menghormati, gotong royong dan penggunaan bahasa daerah dalam komunikasi sehari-hari.

Selain itu, dengan adanya klaim beberapa budaya yang dimiliki Indonesia diakui oleh bangsa lain karena tidak dilestarikan dan tidak dijaga, menunjukkan bahwa masyarakat saat ini lebih cenderung menyukai budaya bangsa lain, yang mana jika dicermati budaya tersebut belum tentu sesuai dengan budaya bangsa Indonesia, dan kelunturan budaya mulai terjadi karena lebih cenderung mengadopsi budaya dari luar daripada melestarikan budaya yang kita miiki sendiri. Dengan demikian, perlu adanya upaya mengembalikan posisi pendidikan sebagai proses pembudayaan untuk mewujudkan manusia dan masyarakat Indonesia yang beradab (civilized human being), sesuai dengan konteks sosial dan budayanya.

Lembaga pendidikan nonformal seperti PKBM merupakan salah satu tempat untuk dapat mengenalkan budaya lokal pada masyarakat. Menurut Idi (2011:69) sekolah bisa menjadi media kontrol sosial (sosial control) dalam proses pelestarian nilai-nilai budaya lokal yang ada di masyarakat. Konservasi nilainilai budaya lokal yang dilakukan sekolah dijadikan sebagai alat untuk mempertahankan nilai-nilai budaya lokal yang ada di masyarakat.

Penyelenggaraan pendidikan berbasis budaya di Yogyakarta salah satunya dalam pendidikan non formal yaitu PKBM. PKBM berperan penting untuk masyarakat dalam mengembangkan dan melestarikan budaya yang ada di Yogyakarta bukan hanya pendidikan formal saja yang berperan untuk pelestarian budaya dalam sektor pendidikan. PKBM yang memiliki Program pendidikan berbasis budaya yaitu PKBM Wiratama, banyak PKBM yang tersebar di daerah Yogyakarta tapi jarang sekali yang memiliki program pendidikan berbasis budaya, PKBM Wiratama sendiri mengadakan kegiatan pembelajaran membatik, oleh karena itu PKBM Wiratama menjadi pilihan untuk penelitian.

\section{METODE PENELITIAN}

\section{Jenis Penelitian}

Penelitian ini menggunakan pendekatan kualitatif. Menurut Sugiyono (2010 : 06) bahwa metode penelitian pendidikan dapat diartikan sebagai cara ilmiah untuk mendapatkan data yang valid dengan tujuan dapat ditemukan, dikembangkan, dan dibuktikan, suatu pengetahuan tertentu sehingga pada gilirannya dapat digunakan untuk memahami, memecahkan dan mengatisipasi masalah dalam bidang pendidikan kualitatif.

\section{Waktu dan Tempat Penelitian}

Penelitian dilaksanakan di PKBM Wiratama, Jalan Tompeyan TR III/162 RT 03 RW 01 Kecamatan Tegal Rejo Kota Yogyakarta. Penelitian dilaksanakan mulai bulan April 2016 sampai Mei 2016.

\section{Target/Subjek Penelitian}

Dalam penelitian ini subyek penelitiannya adalah pelaksanaan pembelajaran pendidikan berbasis budaya Yogyakarta di PKBM Wiratama. 


\section{Diklus: Jurnal Pendidikan Luar Sekolah, 1(1), Maret 2017 - 56}

Noni Felani

Sumber penelitian berasal dari pengelola, tutor, dan peserta didik yang melaksanakan pendidikan berbasis kebudayaan Yogyakarta di PKBM Wiratama

\section{Prosedur}

Penelitian ini dilakukan dengan beberapa tahap, meliputi:

1. Penyusunan proposal

2. Perijinan

3. Pengumpulan data

4. Analisis data

5. Penyusunan laporan penelitian

\section{Data, Intrumen, dan Teknik Pengumpulan} Data

Menurut Sugiyono (2010:78), instrumen penelitian adalah suatu alat yang digunakan untuk mengukur fenomena alam maupun sosial yang diamati secara spesifik, semua fenomena ini disebut variable penelitian. Dari pendapat di atas, dapat disimpulkan bahwa instrumen penelitian adalah alat pengukuran data yang digunakan penelitian untuk mengidentifikasi besar kecilnya objek atau gejala dalam variable penelitian. Dalam penelitian ini yang menjadi intrumen penelitian utama adalah peneliti sendiri. Instrumen pendukung yang digunakan untuk mengungkapkan data dalam penelitian adalah pedoman observasi, pedoman wawancara dan dokumentasi. Instrumen tersebut dikembangkan peneliti berdasarkan indikator dari masing masing yang diteliti. Dalam penelitian ini menggunakan teknik pengumpulan data sebagai berikut : 1 . pengamatan atau observasi, maksudnya adalah mengamati langsung mengenai pelaksanaan kegiatan suatu obyek yang diteliti meliputi pelaksanaan, faktor pendukung dan penghambat pelaksanaan pembelajaran. 2 . Wawancara (interview), Wawancara digunakan untuk menggali data secara mendalam sebagai kelengkapan untuk memperoleh makna dari informasi yang dikumpulkan melalui pengamatan. Wawancara dalam penelitian ini adalah tanya jawab kepada pengelola, tutor dan peserta didik PKBM "Wiratama" atau informan yang dianggap mengerti dan mengetahui permasalahannya. 3. Dokumentasi sebagai teknik pengumpulan data dengan cara mengadakan pencatatan atau pengutipan data dari dokumen yang ada di lokasi penelitian. Study dokumentasi dimaksudkan untuk melengakapi data dari hasil wawancara dan pengamatan.

\section{Teknik Analisis Data}

Penelitian ini menggunakan teknik analisis data menurut Moleong (2005:248), meliputi: (1) Tahap display data, (2) Tahap reduksi data, (3) Tahap penarikan kesimpulan.

\section{HASIL PENELITIAN DAN}

\section{PEMBAHASAN}

Hasil penelitian ini adalah sebagai berikut:

\section{a. Persiapan}

Persiapan adalah menentukan rumusan pembelajaran berupa tujuan, media, sumber belajar, materi, metode pembelajaran, evaluasi yang diterapkan, dan alokasi waktu yang diperlukan dalam pembelajaran (Umberto Sihombing, 2000: 58). 
Diklus: Jurnal Pendidikan Luar Sekolah, 1(1), Maret 2017 - 57

Noni Felani

Persiapan yang dilakukan PKBM

Wiratama dalam kegiatan pendidikan berbasis budaya yaitu:

1. Ketua dan pengelola PKBM merekrut tutor sebagai pendidik yang akan mengajari pembelajaran membatik dan juga merekrut warga belajar sebagai penerima pembelajaran membatik

2. Merencanakan proses pelaksanaan kegiatan pembelajaran membatik dimana ketua, pengelola, tutor dan warga belajar berkumpul untuk menentukan menentukan materi keterampilan membatik dan menyiapkan media serta sarana dan prasarana membatik seperti ruangan, sumber belajar buku pelatihan membatik yang dimiliki tutor dan media pembelajaran yaitu peralatan membatik.

3. Merencanakan jadwal pembelajaran, kapan waktu pelaksanaan kegiatan pembelajaran membatik, serta dimana tempat pelaksanaan kegiatan pembelajaran membatik tersebut.

Dapat disimpulkan bahwa persiapan yang dilakukan adalah merekrut tutor dan warga belajar pembelajaran membatik kemudian mentetukan materi, menyiapkan media pembelajaran, sarana dan prasarana serta menentukan jadwal pembelajaran, kapan dan dimana pelaksanaan pembelajaran membatik.

Sehingga tahapan yang dilakukan sesuai dengan persiapan program Pendidikan Luar Sekolah PLS (Pendidikan Luar Sekolah).

\section{b. Pelaksanaan}

Tahap pelaksanaan merupakan aktivitas pembelajaran bukan hanya proses penyampaian dan penerimaan informasi tapi juga memberikan pengalaman belajar kepada peserta didik. Pengalaman ini harus memberikan dorongan untuk mengubah tingkah laku peserta didik seperti yang diinginkan. Dalam tahap pelaksanaan pembelajaran. Menerapkan strategi dan metode pembelajaran yang sudah dirumuskan. Pendidik memberikan materi pembelajaran (Umbeto Sihombing, 2000:65).

Pelaksanaan pendidikan keterampilan membatik di PKBM Wiratama diawali dengan saling berjabat tangan ketika hadir antara warga belajar dengan tutor. Kemudian dilanjutkan dengan dengan do'a bersama sebelum memulai pelaksanaan pendidikan keterampilan membatik. Setelah berdo'a tutor mengabsen warga belajar, kemudian menyampaikan materi dengan jadwal yang telah ditentukan pada saat itu.

Pelaksanaan pendidikan berbasis budaya dalam hal ini adalah membatik dimulai dengan cara tutor menyampaikan materi tentang membatik baik secara materi maupun praktik. Tutor menjelaskan tentang materi dan media yang digunakan dalam pembelajaran, serta mendampingi warga 


\section{Diklus: Jurnal Pendidikan Luar Sekolah, 1(1), Maret 2017 - 58 Noni Felani}

belajar dalam proses pembelajaran yang sedang berlangsung.

Dalam pelaksanaan pembelajaran pendidikan berbasis budaya di PKBM Wiratama terdapat beberapa hal yang ada di dalam Pelaksanaan tersebut:

1) Waktu Pelaksanaan

Menurut Hamalik (2005:35-36), lamanya waktu pelaksanaan pelatihan berdasarkan pertimbangan berikut:

(a) Jumlah dan mutu kemampuan yang hendak dipelajari dalam pelatihan tersebut lebih banyak dan lebih tinggi bermutu, kemampuan yang ingin diperoleh mengakibatkan lebih lama diperlukan pelatihan. (b) Kemampuan belajar para peserta dalam mengikuti kegiatan pelatihan. Kelompok peserta yang ternyata kurang mampu belajar tentu memerlukan waktu latihan yang lebih lama. (c) Media pengajaran, yang menjadi alat bantu bagi peserta dan pelatih. Media pengajaran yang serasi dan canggih akan membantu kegiatan pelatihan dan dapat mengurangi lamanya pelatihan tersebut.

Dalam pelaksanaan pembelajaran terdapat keputusan yang dibuat untuk menentukan waktu pembelajaran dan tempat pelaksanaan pembelajaran tersebut agar dapat terjadwal dengan baik. Sehingga warga belajar dan tutor dapat melakukan pembelajaran sesuai dengan jadwal yang telah ditentukan atau yang telah dibuat serta mengetahui kapan dan dimana terlaksananya kegiatan tesebut.
Pelaksanaan kegiatan pembelajaran keterampilan membatik dilaksanakan selama 6 bulan, yaitu dilakukan 2 kali seminggu dan biasanya dilaksanakan pada hari rabu, pukul 15.00-17.00 WIB atau sampai selesai, pelaksanaan kegiatan keterampilan membatik tidak terjadwal dengan runtut karena kadang kegiatan keterampilan tersebut diundur atau ada kegiatan keterampilan yang mendadak dari narasumber yang ingin memberikan pelatihan di PKBM Wiratama dan juga apabila tutor membatik berhalangan hadir karena hal tertentu sehingga diharuskan kegiatan tersebut ditunda pada minggu berikutnya.

2) Sarana dan Prasarana

Menurut Mulyasa (2003:49), Sarana pendidikan adalah peralatan dan perlengkapan yang secara langsung dipergunakan dan menunjang proses pendidikan, khususnya proses belajar mengajar, seperti gedung, ruang kelas, meja, kursi, serta alat-alat dan media pengajaran. Sedangkan, prasarana pendidikan adalah fasilitas yang secara tidak langsung menunjang jalannya proses pendidikan atau pengajaran, seperti halaman, kebun, jalan menuju sekolah, dan taman sekolah.

Dari hasil observasi dan wawancara sarana dan prasarana yang dimiliki oleh PKBM Wiatama sudah tersedia seperti tempat untuk praktik membatik dan alat alat membatik juga sudah tersedia tetapi tempat untuk praktik membatik tidak luas sehingga 
Diklus: Jurnal Pendidikan Luar Sekolah, 1(1), Maret 2017 - 59

Noni Felani

apabila pembelajaran dihadiri oleh warga belajar cukup banyak ruangan akan sempit dan ada alat membatik yang kurang sehingga digunakan secara bersamaan.

3) Pelaksana

dalam Implementasi

Pembelajaran Berbasis Budaya

Menurut Kamus Besar Bahasa Indonesia (2008) definisi dari kata Pelaksana merupakan orang (panitia, organisasi, dan sebagainya) yang mengerjakan atau melaksanakan (rancangan dan sebagainnya).

Pelaksanaan proses pembelajaran pendidikan berbasis budaya yang dilaksankan oleh PKBM Wiratama yaitu kegiatan membatik, dalam pelaksanaan tesebut terdapat beberapa orang pelaksana kegiatan yang terlibat dalam pelaksana kegiatan tersebut seperti tutor sebagai pengajar, warga belajar sebagai peserta kegiatan membatik, pengelola sebagai pembuat perencanaan dan pengelola kegiatan.

4) Media dan Sumber Belajar

Media adalah segala sesuatu yang dapat digunakan untuk menyalurkan pesan dari pengirim dan penerima sehingga dapat merangsang pikiran, perasaan, perhatian, minat, dan perhatian peserta didik sedemikian rupa sehingga terjadi proses belajar, serta dapat mencapai tujuan. (Syaiful Bahri Djamarah dan Aswan Zain, 2010:41)

Sedangkan sumber belajar adalah semua sumber baik berupa data orang dan wujud tertentu yang dapat digunakan oleh peserta didik dalam belajar, baik secara terpisah maupun secara terkombinasi sehiggga mempermudah peserta didik dalam mecapai tujuan belajar atau mencapai kompetensi tertentu.

(www.pskgjppkhbcilegon.com)

Media merupakan alat bantu yang digunakan dalam proses pembelajaran. Media yang digunakan harus disesuaikan dengan materi yang disampaikan, dimaksudkan agar warga belajar terbantu dalam memahami atau menerima materi pembelajaran yang di sampaikan oleh tutor. Dalam pembelajaran pendidikan berbasis budaya di PKBM Wiratama yaitu membatik, media yang digunakan tutor adalah canting, kompor kecil, wajan kecil, malam, kain, pensil, dan buku panduan membatik yang dimiliki tutor untuk pedoman dan sumber belajar dalam pratik membatik, sumber belajar yang digunakan tutor dalam pembelajaran membatik adalah buku panduan membatik yang dimiliki tutor sendiri.

5) Evaluasi Pembelajaran

Evaluasi merupakan proses pengumpulan data untuk menentukan sejauh mana, dalam hal apa, dan bagaimana tujuan pendidikan sudah tercapai (Suharsimi Arikunto, 2010:3)

Menurut Kourilski dalam Oemar Hamalik (2011:145), evaluasi adalah tindakan tentang penetapan derajat penguasaan atribut tetentu oleh individu atau kelompok. Ini berarti evaluasi dimaksudkan untuk mengamati hasil 


\section{Diklus: Jurnal Pendidikan Luar Sekolah, 1(1), Maret 2017 - 60}

Noni Felani

belajar peseta didik dan berupaya menentukan bagaimana menciptakan kesempatan belajar.

Evaluasi pembelajaran berbasis budaya dilakukan pada akhir pembelajaran untuk mengetahui pemahaman warga belajar dalam mengikuti pembelajaran dan untuk mengetahui apakah perencanaan pembelajaran sudah berjalan sesuai dengan harapan awal atau tidak. Evaluasi merupakan suatu proses yang penting dalam pelaksanaan pembelajaran karena untuk mengetahui permasalahan yang sedang terjadi atau yang menjadi kendala atau penghambat dalam suatu pelaksanaan pembelajaran sehingga nantinya akan dicarikan solusi terkait dengan pemasalahan yang ada dan adanya evalusi pembelajaran pengelola dan tutor agar dapat selalu memperbaiki proses pembelajaran sehingga kualitas pembelajaran akan meningkat, biasanya kegiatan evaluasi pembelajaran dilakukan diakhir pembelajaran.

Faktor pendukung pelaksanaan pendidikan berbasis budaya di PKBM Wiratama:

1) Tutor yang menguasai materi dalam melaksanakan pembelajaran membatik

2) Strategi pelaksanaan pembelajaran yang sesuai dengan situasi dan kondisi warga belajar

3) Sarana dan Prasana pembelajaran yang sudah tersedia

Faktor penghambat yang terdapat pada pelaksanaan pembelajaran membatik di PKBM Wiratama:
1) Kurangnya dana untuk membeli alat dan bahan keperluan untuk pembelajaran

2) Cuaca buruk atau Hujan

\section{KESIMPULAN DAN SARAN}

\section{Kesimpulan}

Berdasarkan hasil penelitian dan pembahasan yang telah dilakukan dapat ditarik kesimpulan sebagai berikut:

a. Persiapan

Ketua dan pengelola PKBM merektut tutor dan warga belajar kemudian ketua, pengelola, tutor dan warga belajar berkumpul untuk merencanakan proses pelaksanaan kegiatan pembelajaran membatik serta menentukan jadwal pembelajaran.

b. Pelaksanaan

Pembelajaran membatik dimulai dengan cara tutor menyampaikan materi tentang membatik baik secara materi maupun praktik. Tutor menjelaskan tentang materi dan media yang digunakan dalam pembelajaran, serta mendampingi warga belajar dalam proses pembelajaran yang sedang berlangsung.

c. Waktu Pelaksanaan

Dilaksanakan selama 6 bulan, yaitu dilakukan 2 kali satu bulan dan biasanya dilaksanakan pada hari rabu, pukul 15.00-17.00 WIB atau sampai selesai.

d. Sarana dan Prasarana

Sarana dan prasarana yang dimiliki oleh PKBM Wiatama sudah tersedia seperti tempat untuk praktik membatik dan 
alat alat membatik juga sudah tersedia tetapi tempat untuk pratik membatik tidak luas sehingga apabila pembelajaran dihadiri oleh warga belajar cukup banyak ruangan akan sempit dan ada alat membatik yang kurang sehingga digunakan secara bersamaan.

e. Pelaksana dalam Implementasi Pembelajaran Berbasis Budaya

Pelaksana kegiatan yang terlibat dalam pelaksaan kegiatan tersebut adalah tutor sebagai pengajar, warga belajar sebagai peserta kegiatan membatik, pengelola sebagai pembuat perencanaan dan pengelola kegiatan.

f. Media dan Sumber Belajar

Media yang digunakan adalah canting, kompor kecil, wajan kecil, malam, kain, pensil, dan buku panduan pelatian membatik yang dimiliki tutor untuk pedoman dan sumber belajar dalam pratik membatik.

g. Evaluasi Pembelajaran

Dilakukan pada akhir pembelajaran dengan cara berdiskusi atara pengelola, tutor, dan ketua PKBM mereka mendiskusikan nya dengan tanya jawab untuk mencari solusi apabila terdapat permasalahan yang terjadi dalam proses pembelajaran.
Faktor Pendukung Pelaksanaan
Pendidikan Berbasis Budaya di PKBM
Wiratama

1) Tutor yang menguasai materi dalam melaksanakan pembelajaran membatik

2) Strategi pelaksanaan pembelajaran yang sesuai dengan situasi dan kondisi warga belajar

3) Sarana dan Prasana pembelajaran yang sudah tersedia

Faktor Penghambat Pelaksanaan Pendidikan Berbasis Budaya di PKBM Wiratama

1) Kurangnya dana untuk membeli alat dan bahan keperluan untuk pembelajaran

2) Cuaca buruk atau Hujan

\section{Saran}

1. PKBM Wiratama agar menjalin kerjasama dengan lembaga keuangan yang memiliki dana cukup memadai dengan bunga ringan, seperti BRI dengan program KUR ( Kredit Usaha Rakyat)

2. Penambahan tempat pembelajaran karena tempat pembelajaran yang ada saat ini sempit apabila warga belajar yang mengikuti pembelajaran bertambah.

\section{DAFTAR PUSTAKA}

Ahmad Rohani. H.M dan Abu Ahmadi. 1991. Pengelolaan Pengajaran. Jakarta:Rineka Cipta.

Alwasilah, A. Chaedar. 2006. Pokoknya Sunda. Bandung: Pustaka Jaya 


\section{Diklus: Jurnal Pendidikan Luar Sekolah, 1(1), Maret 2017 - 62}

Noni Felani

Arikunto, S. 2010. Prosedur Penelitian

Suatu Pendekatan Praktik. Yogyakarta:

Rineka Cipta

Balai Pengembangan Kegiatan Belajar (BPKB). 2013. Pengelolaan PKBM Gaya Yogyakarta. DIY: Tidak ada terbitan

Dewantara, K.H. 2004. Bagian pertama: pendidikan. Yogyakarta: Majelis

Luhur Persatuan Tamansiswa.

Direktorat Pembinaan Pendidikan Masyarakat Direktorat Jenderal

Pendidikan Anak Usia Dini Nonformal Dan Informal Kementerian Pendidikan

Dan Kebudayaan .(2012). Standar Dan

Prosedur Penyelenggaraan Pusat

Kegiatan Belajar Masyarakat (Pkbm).

Jakarta: Tidak ada terbitan

Endarmoko, E. 2006. Kamus Bahasa Indonesia. Jakarta. EGC

http://yogyakarta.bpk.go.id Di unduh pada

hari Rabu 11 Nopember 2015. Pukul

12.15

http://ipabi.org Di unduh pada hari kamis

11 Februari 2016. Pukul 10.45

http://library.binus.ac.id/eColls/eThesisdoc/

Bab1HTML/2011201622MCBab1001/p

age9.html Di unduh pada hari sabtu 14

Juni 2014. Pukul 15:36

http://staff.uny.ac.id/sites/default/files/penel

itian/Entoh\%20Tohani,\%20S.Pd.,\%20

M.Pd./Microsoft \%20Word\%20\%20ST

RATEGI\%20PENGEMBANGAN\%20

KAPASITAS\%20PKBM.pdf Di unduh pada hari senin 8 Februari 2016. Pukul $20: 38$

http://www.pskgjppkhbcilegon.com/ Di unduh senin 21 Nopember 2016. Pukul $20: 36$

Idi, A. 2011. Sosiologi pendidikan: individu,sekolah dan pendidikan. Jakarta:Rajawali Pers

Jumhari. 2014. Pelaksanaan Pembelajaran Pendidikan Kecakapan Hidup (PKH) Pada Program Paket B di PKBM Bhakti Persada, Bantul DIY. Skripsi FIP PLS UNY

Kamus Besar Bahasa Indoonesia Edisi Keempat. 2008. Jakarta: Gramedia Pustaka Utama

Koentjaraningrat. 2011. Pengantar Ilmu Antropologi. Jakarta: Radar Jaya Offset Maryati. 2013. Pelaksanaan Pendidikan Ketrampilan Paket B Berbasis Muatan Lokal di Pusat Kegiatan Belajar Masyarakat (PKBM) Suka Makmur, Jetis Saptosari Gunung Kidul. Skripsi FIP PLS UNY

Mardiatmadja B.S. 2006. Tantangan Dunia Pendidikan. Yogyakarta: Penerbit Kanis

M.J. Herskovits.2006. Antropologi Suatu Pengantar. Jakarta : PT Raja Grafindo Moleong, Lexy. 2002. Metodologi Penelitian Kualitatif. Bandung: PT Remaja Rosdakarya

Moleong, Lexy. 2005. Metode Penelitian Kualitatif. Bandung: PT Remaja Rosdakarya 
Muzakki, Muzakki; Fauziah, Puji Yanti. Implementasi Pembelajaran Anak Usia Dini Berbasis Budaya Lokal di PAUD Full Day School. Jurnal Pendidikan dan Pemberdayaan Masyarakat, [S.1.], v. 2, n. 1, p. 39-54, mar. 2015. ISSN 24772992.

Available

at: $<$ http://journal.uny.ac.id/index.php/jp pm/article/view/4842>. Date accessed: 05 apr. 2016.

Mulyasa, E. 2003. Manajemen Berbasis

Sekolah. Bandung: PT. Remaja Rosdakarya

Nana Sudjana dan Ahmad Rivai. 2007.

Teknologi Pengajaran. Bandung: Sinar Baru Algesindo

Nurdin, Syafruddin dan Usman, Basyiruddin. 2003. Guru Profesional dan Implementasi Kurikulum. Jakarta: Ciputat Press.

Oemar, Hamalik. 2003. Proses Belajar Mengajar. Jakarta: Bumi Aksara.Soetomo

Oemar, Hamalik. 2005. Manajemen Pendidikan dan Pelatihan. Bandung: Y.P Pemindo

PKBM Wiratama. 2013. Arsip Dokumen PKBM. Yogyakarta: Tidak ada terbitan Ranjabar. 2006. Sistem Sosial Budaya Indonesia Suatu Pengantar. Bandung. Ghalialad

Role of Community Learning Center for the Promotion of Literacy and Quality of Life. April1999. Pdf
Rumidi, Sukandar. 2004. Metode Penelitian Petunjuk Praktis Untuk Penelitian Pemula. Yogyakarta: Gajah Mada Yogyakarta Press

Sayuti, A, Suminto. 2005. Menuju Situasi Sadar Budaya Antara Yang Lain Dan Kearifan Lokal. Makalah: Universitas Negeri Yogyakarta

Soelaeman, Munandar, M. 2005. Ilmu Budaya Dasar. Bandung:Refika Aditama

Sugiyono. 2010. Metode Penelitian Pendidikan. Bandung: Alfabeta

Sulaiman. 2002. Struktur Sosial dan Nilai Budaya Masyarakat Pedesaan. Yogyakarta: APD

Sutrisno, Mudji dan Hendar Putanto. (eds) 2014. Teori Teori Kebudayaan. Yogyakata: Kanisius

Syaiful Bahri Djamarah \& Asqan Zain. 2010. Strategi Belajar Mengajar. Bandung: PT. Remaja Rosdakarya.

Tilaar. 2002. Pendidikan kebudayaan, dan masyarakat madani indonesia.

Bandung: PT Remaja Rosdakarya.

Umberto Sihombing. 2000. Pendidikan

Luar Sekolah Managemen Strategi. Jakarta: PD Mahkota

UU Nomor 13 Tahun 2012 Tentang Kewenangan Urusan Daerah Keistimewaan. 